\title{
Preparation \& Characterization of Insulating Rice Husk Ash Refractory using Rice Husk as Pore Forming Agent
}

\author{
SK Saddam Hossain ${ }^{1}$, Aman Bhardwaj², Manas Ranjan Majhi ${ }^{3}$ \\ ${ }^{1}$ Department of Ceramic Engineering, Indian Institute of Technology (BHU) Varanasi- 221005, India
}

\begin{abstract}
Preparation of the Insulating Silica Refractory was done by utilizing the waste Rice Husk Ash taken from rice mills. These insulating properties can be obtained by controlling the porosity of the sample by using different amount of rice husk as pore forming media and different firing temperatures. Experimental compositions were prepared by RHA whose chemical composition were determined by $X-R F$. Rectangular samples were prepared using hydraulic press. Physical properties like Apparent Porosity was found to be favorable for Thermal Insulation and was observed to be increasing with increasing the amount of pore forming agent (Rice Husk). Mechanical strength were found to be good considering the porosity present. In addition the Crystalline phase were also been studied by XRD analysis.
\end{abstract}

Keywords: Pore forming agent, Waste Rice Husk, Rice Husk Ash, Insulation, Silica.

\section{Introduction}

Globally, 650 Tons of Rice Paddy are produced every year. Around $20 \%$ of the rice paddy produces Rice Husk. Rice husk is produced as a waste from its grain during its processing in rice mills and its removal during rice refining. It creates disposal problem [1]. This rice husk generally contains $70-80 \%$ organic matter such as cellulose, lignin etc. and rest $20-30 \%$ mineral components such as silica, alkalis and trace elements [2-5]. When rice husk is burnt into open environment, it produces another residue called Rice Husk Ash. This burnt RHA has different chemical, mineralogical and morphological characteristics depending on the process acquired during burning of the husk as well as on the rice variety, soil chemistry, climatic conditions, and even the geographic localization of the culture [6-7].

Insulation silica refractories are generally used for insulation lining of furnace or kiln so that energy efficiency can be maintained which responds into cost beneficiation as well as reduction in the production of flue gases.

It contains $60-70 \%$ of $\mathrm{SiO}_{2}$ which comes from raw-material used like quartz and clays. Here, silica can be provided through RHA as it contains it in amorphous phase. This amorphous silica shows better reactivity than crystalline silica present in quartz. So, insulation silica refractories can be successfully prepared using RHA [8-11].

In the present Investigation, we have studied the effect of pore forming agent used in insulation refractory prepared by RHA. Here rice husk its self was used as pore forming agent in different amount in different samples prepared. It's also noted to be a benefit as most of the raw- material of this insulation refractory has come from waste.

\section{Materials \& Methods}

\subsection{RH \& RHA}

RHA were collected from rice mill where $\mathrm{RH}$ is used as a fuel. This RHA has already been burnt around $400^{\circ} \mathrm{C}$ several times in the furnace in the mill. So, it has a trace amount of volatile matter which provides us a potential to use it directly without any further treatment. The chemical composition was determined by using the X-ray fluorescence (XRF) spectrometer according to ASTM C114-00.

Table 1: Chemical composition of rice husk ash by XRF

\begin{tabular}{|c|c|c|c|}
\hline Compound & Concentration (\%) & Compound & Concentration (\%) \\
\hline $\mathrm{SiO}_{2}$ & 85.3 & $\mathrm{ZnO}$ & 0.11 \\
\hline $\mathrm{P}_{2} \mathrm{O}_{5}$ & 3.8 & $\mathrm{CuO}$ & 0.058 \\
\hline $\mathrm{K}_{2} \mathrm{O}$ & 2.37 & $\mathrm{Rb}$ & 0.036 \\
\hline $\mathrm{CaO}$ & 1.42 & $\mathrm{BaO}$ & 0.03 \\
\hline $\mathrm{Fe}_{2} \mathrm{O}_{3}$ & 0.817 & $\mathrm{ZrO}_{2}$ & 0.02 \\
\hline $\mathrm{MgO}$ & 0.81 & $\mathrm{Re}_{2} \mathrm{O}_{7}$ & 0.02 \\
\hline $\mathrm{MnO}$ & 0.312 & $\mathrm{Y}_{2} \mathrm{O}_{3}$ & 0.012 \\
\hline $\mathrm{RuO}$ & 0.271 & $\mathrm{Eu}_{2} \mathrm{O}_{3}$ & 0.01 \\
\hline $\mathrm{SO}_{3}$ & 0.23 & $\mathrm{Cr}_{2} \mathrm{O}_{3}$ & 0.014 \\
\hline $\mathrm{TiO}_{2}$ & 0.18 & $\mathrm{NiO}$ & 0.008 \\
\hline
\end{tabular}

It was found that RHA contains $85 \%$ of $\mathrm{SiO}_{2}$. So, it can be used as a raw- material for the replacement of quartz in insulation silica refractory.

The XRD analysis of RHA were recorded from $10^{\circ}$ to $90^{\circ}$ range of $2 \Theta$ in Rigaku Mini Flex-II desktop X-ray Diffractometer". The XRD pattern of the rice husk ash (RHA), shown in Fig. (1), indicates that silica in the rice husk exists in the amorphous form only. 


\section{International Journal of Science and Research (IJSR) \\ ISSN (Online): 2319-7064}

Index Copernicus Value (2013): 6.14 | Impact Factor (2014): 5.611

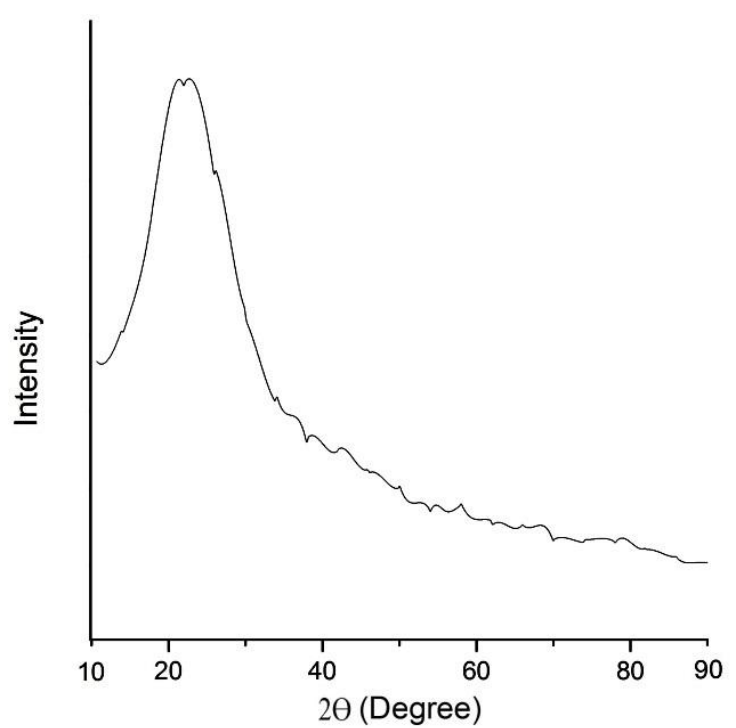

Figure 1: XRD Analysis of RHA

Rice husk has about $80 \%$ of volatile matter which is removed when it is set to burn at $200^{\circ}$ to $500^{\circ}$. It can be assumed that if $\mathrm{RH}$ powder is used in as pore forming agent than during the sintering of the body, it will produce pores by combusting itself which is a fundamental requirement of insulating refractory. This was confirmed by performing the Thermal Gravimetric Analysis (TGA) up to $1000^{\circ} \mathrm{C}$ in air atmosphere with heating rate of $10^{\circ} \mathrm{C} / \mathrm{min}$ in Setaram-Scientific and Industrial Equipment (Model no-560/51920)"

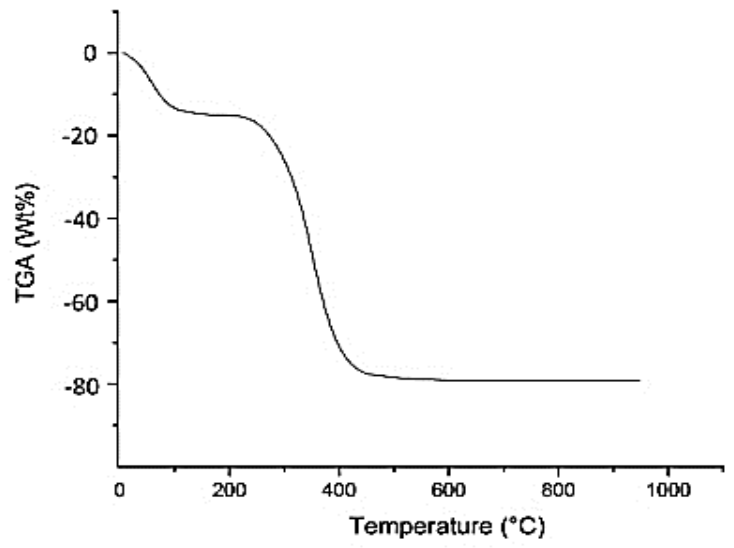

Figure 2: TGA curve for RH up to $1000^{\circ} \mathrm{C}$.

\subsection{Sample Preparation}

The fabrication of the refractory was done from several different formulations containing rice husk ash, rice husk, clay as binder and refractory grog for strengthening. Different sample prepared are tabulated in Table-2. Mixing of constituents was done manually for 20 minutes in dry condition. By following semi-dry process, least amount of water was used. The rice husk ash refractories were formed by the pressing method in a hydraulic press and moulded into rectangular form. The clay also provided green strength to the body and better workability.
Table 2: Percentage of Rice Husk

\begin{tabular}{|c|c|c|c|c|c|c|}
\hline Sample & S-1 & S-2 & S-3 & S-4 & S-5 & S-6 \\
\hline \% Rice Husk & 5 & 10 & 15 & 20 & 25 & 30 \\
\hline
\end{tabular}

\subsection{Drying \& Sintering}

The prepared samples were allowed to dry in an electric oven at a temperature of $105^{\circ} \mathrm{C}$ for $6 \mathrm{hrs}$. The samples were sintered in a Bysake \& Co. Electric Furnace (Model No7054 )" with a heat schedule of room temperature to $500^{\circ} \mathrm{C}$ in $4 \mathrm{hrs}$ and thereafter up to $1180^{\circ} \mathrm{C}$ in $2 \mathrm{hrs}$. The soaking period was kept 1 hour and cooling was done for $7 \mathrm{hrs}$.

\section{Result \& Discussion}

\subsection{Apparent Porosity \& Bulk Density}

The boiling water method described in the ASTM C20 [12] was used to determine the apparent porosity (AP) and the bulk density (BD). It has been observed that porosity increases gradually with increasing the amount of RH.

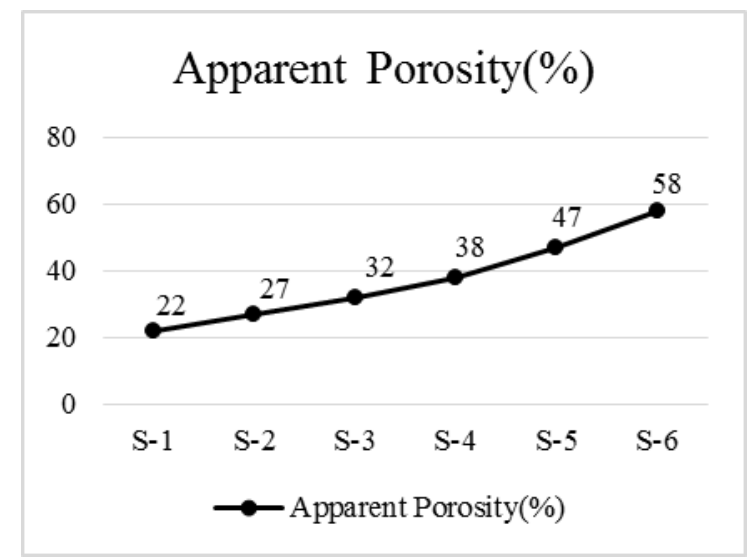

Figure 3: Apparent porosity of Sintered Samples

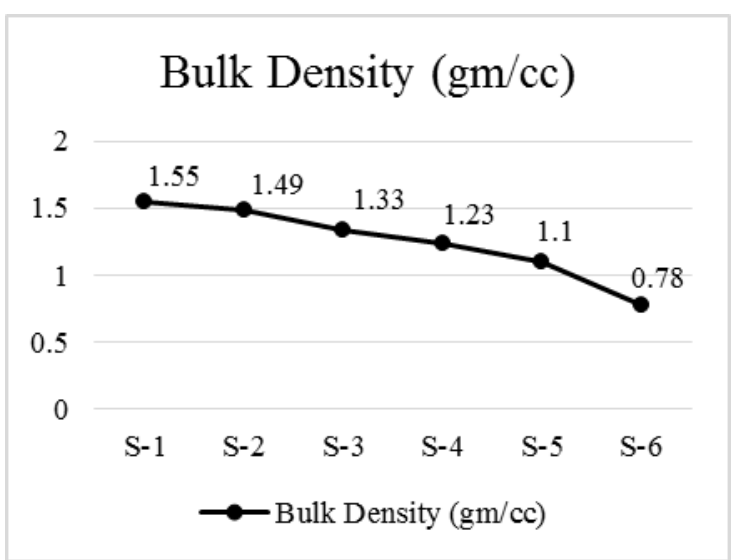

Figure 4: Bulk Density of Sintered Samples

\subsection{Modulus of Rupture}

The MOR was determined according to ASTM 133 [13]. It has been seen that MOR of these insulation refractory as very good considering the amount of porosity present in them. It may be a result of incorporating refractory grogs and clay into the composition which enhanced these mechanical properties of the product. 


\section{International Journal of Science and Research (IJSR) \\ ISSN (Online): 2319-7064}

Index Copernicus Value (2013): 6.14 | Impact Factor (2014): 5.611

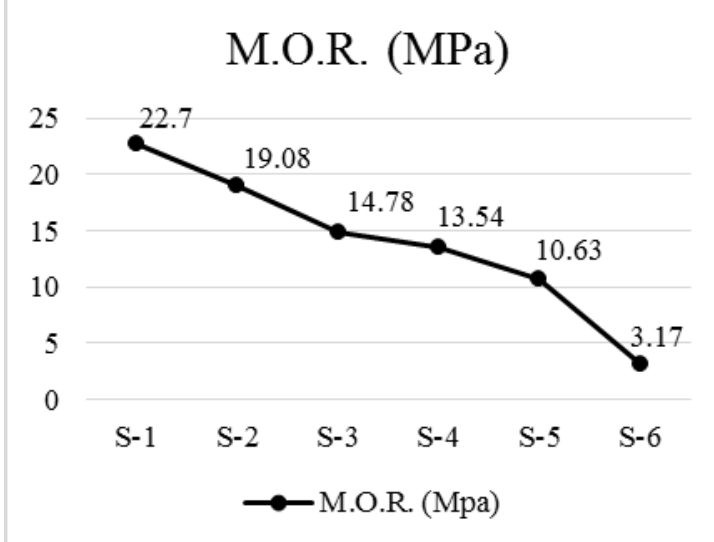

Figure 5: Modulus of Rupture of Sintered Samples

\subsection{Thermal Conductivity}

Standard method for determining thermal conductivity of refractories by Hot Cross-Wire method as per ASTM C-1113 were used. The thermal conductivity tests are particularly important for insulating refractories where the thermal gradients from the hot face to the cold face dictate the use of a refractory material for the specific uses. The tests were performed at $800^{\circ} \mathrm{C}$. The low thermal conductivity values of this Insulating refractory may be due to their porous nature, grain boundaries and other microscopic imperfections.

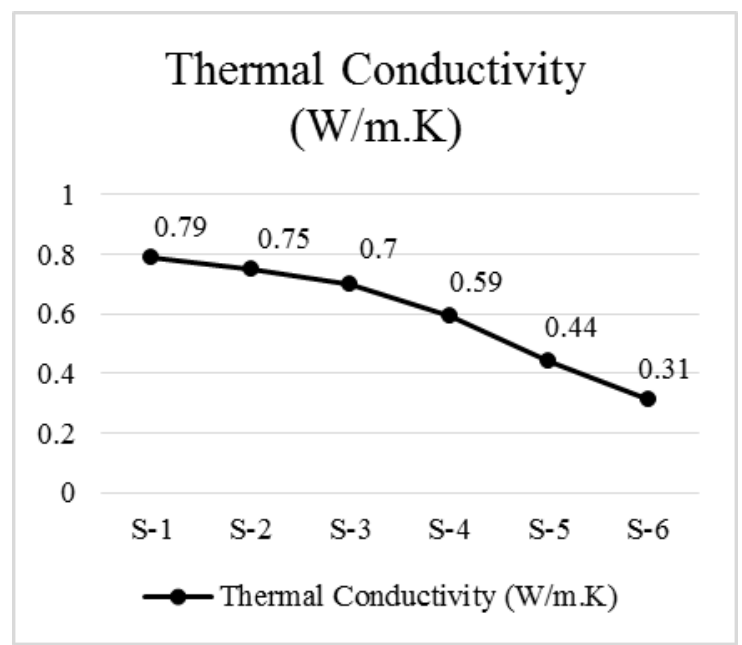

Figure 6: Thermal conductivity at $800^{\circ} \mathrm{C}$

\subsection{X-Ray Diffraction Analysis}

XRD analysis were done for sample $\mathrm{S}-5$ due to its promising insulation properties. XRD were done at $2 \Theta, 10^{\circ}$ to $70^{\circ}$. The pattern is studied using JCPDS file to identify the phases developed after sintering. The result confirms the presence of crystalline silica $\left(\mathrm{SiO}_{2}\right)$ as the major phase in the rice husk ash refractory. The polymorphs of silica present include both the cristobalite and tridymite.

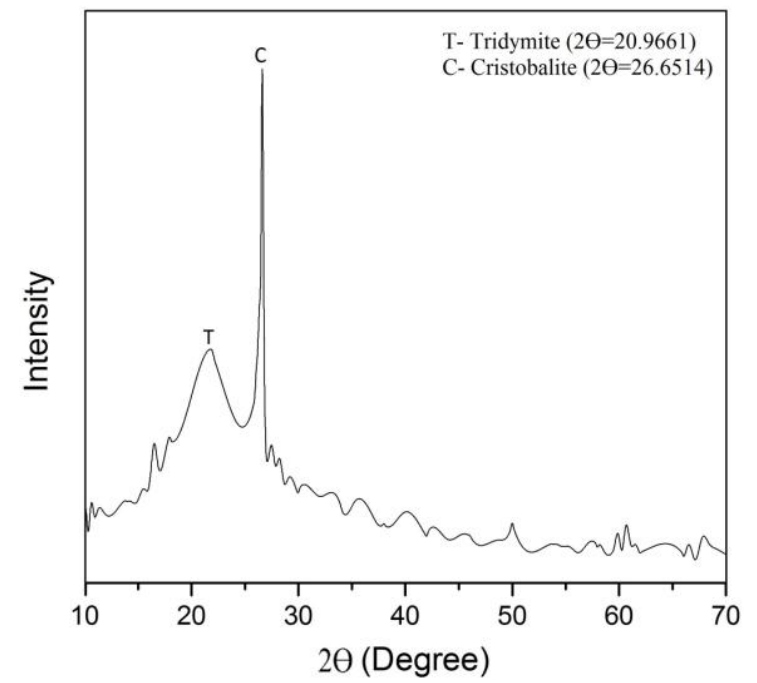

Figure 7: XRD analysis for RHA insulation refractory

\section{Conclusion}

1) The insulating refractory prepared using RHA as the source of silica and $\mathrm{RH}$ as Pore forming agent produced excellent properties in terms of bending strength (MOR) as well as in insulation (Thermal conductivity).

2) The sample S-5 having $25 \%$ of RH has shown excellent insulating property with sustainable mechanical strength. Increasing further amount of RH resulted in an increase in insulation but MOR is decreased drastically. So, the maximum amount of $\mathrm{RH}$ as pore forming agent can be limited up to $25 \%$.

3)It can be observed that RH (as pore forming agent) is favourable for our purpose as when it is combusted, it produced pores in the body and the residue is RHA itself giving silica to the system.

4) The raw-materials used here to prepare insulating refractory contains only industrial wastes like RH, RHA and grogs. It is the key to the benefit in terms of waste disposal as well as its utilization.

\section{Acknowledgement}

We are grateful to the faculty and staff of Department of Ceramic Engineering, IIT (BHU), Varanasi, India for providing the proper facilities to accomplish this work.

\section{References}

[1] J.C.C. Cunha and E.M. Canepa, Aproveitamento energe'tico da casca de arroz.Programa energia," Research Project Report, Fundatec, porto, Alegre RS (1986)

[2] Madhumita Sarangi S. Bhattacharyya and R.C. Behera, Effect of temperature on morphology and phase transformations of Nano crystalline silica obtained from rice husk", 82: 5, 377-386

[3] Ajay kumar, Kalyani Mohanta, Devendra Kumar and Om Parkash, "Properties and Industrial Applications of Rice husk"A review, ISSN 2250-2459, Volume 2, Issue 10 (October 2012) 
[4] Matori K. A, Haslinawati M.M, Producing Amorphous White Silica from Rice Husk". MASAUM Journal of Basic and Applied Sciences, Vol. 1, No. 3, 512 (October 2009)

[5] Adylov G. T., Faiziev Sh. A., Paizullakhanov M. S., Silicon Carbide Materials Obtained from Rice Husk Technical Physics Letters", Vol. 29, No. 3, pp. 221-223 (2003)

[6] Agus setyo muntohar, Utilization of uncontrolled burnt rice husk ash in soil improvement dimensi teknik sipil”, vol. 4, no. 2, 100 - 105, ISSN 1410-9530 (September 2002)

[7] L.O. Guedert, Estudo da viabilidate te'cnica e econômica do aproveitamento da cinza de casca de arroz como material pozol â nico," Master's degree dissertation, UFSC, PPGEPs, Florianópolis, sc (1989)

[8] Mansaray, K. G. And Ghaly, A. E,Thermal, Đegradation of Rice Husks in an Oxygen Atmosphere", Energy Sources, Part A: Recovery, Utilization and Environmental Effects, 21: 5, 453 - 466 (1999)

[9] Fadaly El, Recycling of Ceramic Industry Wastes in Floor Tiles Recipes", Journal of American Science (2010)

[10] M.R.F. Gonzalves and C.P. Bergmann, Thermal insulators made with rice husk ashes: production and correlation between properties and microstructure", Constr. Build Mater. Vol. [21], 12, 2059-2065 (2007)

[11]P.C. Kapur, Thermal insulations from rice husk ash, an agricultural waste", Ceram Int. Vol. [6], 2, 75-78(1990)

[12] ASTM C20: Standard test methods for apparent porosity, water absorption, apparent specific gravity and bulk modulus of burned refractory brick and shapes by boiling water. ASTM International (2010)

[13] ASTM C133: Standard test methods for cold crushing strength and modulus of rupture of refractories. ASTM International

\section{Author Profile}

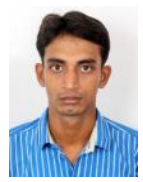

Sk Saddam Hossain received the B.Tech degree in Ceramic Technology from Govt. College of Engineering and Ceramic Technology, Kolkata, India in 2014. He has worked as Project assistant in CGCRI, Kolkata during Sept, 2014 to July, 2015. He is pursuing M.Tech from Department of Ceramic Engineering of Indian Institute of Technology (BHU), Varanasi, India.

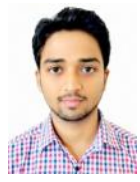

Aman Bhardwaj has completed his B.Tech in Ceramic Engineering at Govt. College of Engineering \& Technology, Bikaner, India in June, 2015. He's currently pursuing his M.Tech in the Department of Ceramic Engineering, Indian Institute of Technology (BHU), Varanasi, India.

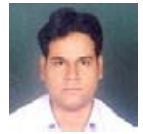

Dr. Manas Ranjan Majhi is Associate Professor in the Department of Ceramic Engineering, Indian Institute of Technology (BHU), Varanasi, India. Dr. Majhi has done a lot of research \& publications in the field of Bio-Ceramics, Advance Refractories Engineering \& Composite Materials. 